\begin{tabular}{|l|l|}
\hline $\begin{array}{l}\text { Postprint } \\
\text { Version }\end{array}$ & 1.0 \\
\hline Journal website & http://onlinelibrary.wiley.com/doi/10.1111/cch.12095/abstract \\
\hline Pubmed link & \\
\hline DOI & $10.1111 /$ cch.12095 \\
\hline
\end{tabular}

This is a NIVEL certified Post Print, more info at http://www.nivel.eu

\title{
Exploring young patients' perspectives on rehabilitation care: methods and challenges of organizing focus groups for children and adolescents
}

\author{
M. KROL ${ }^{1, *}$, H. SIXMA ${ }^{1}$, J. MEERDINK ${ }^{2}$, H. WIERSMA ${ }^{3}$, J. RADEMAKERS ${ }^{1}$ \\ ${ }^{1}$ Patient Experiences and Evaluations, NIVEL, Utrecht, The Netherlands \\ ${ }^{2}$ WESP foundation, Sassenheim, The Netherlands \\ ${ }^{3}$ LSR (National Organisation of Client Councils), Utrecht, The Netherlands
}

\begin{abstract}
Background: In research on quality of care, the experiences of children and (pre)adolescents are usually assessed by asking their parents. However, these young patients may have preferences of their own, and their experiences do not necessarily concur with those of their parents. Therefore, our research aimed to give young patients an opportunity to speak up for themselves.

Methods: Focus group meetings and online focus groups were organized for two age groups (8-11 and 12-15 years) of young patients from two Dutch rehabilitation centres, with the use of a tailored interview technique. The feasibility and applicability of both types of focus groups were assessed.

Results: For both types of focus groups, recruitment proved a major problem. The focus group meetings with (pre)adolescents proved both feasible and applicable in obtaining information regarding the preferences and experiences towards rehabilitation care. Regarding children's meetings, there were mixed results. The setting suited most of them, but some were more anxious. In general, online focus groups were less successful than expected for both age groups.

Conclusions: Possibilities for enhancing the recruitment rate should be considered, as the low participation rates limited generalizability of focus group results. The tailored design proved useful for obtaining relevant input from (pre)adolescents through meetings, but, especially for children, repeated meetings or other locations (e.g. at home) could be considered. This may make
\end{abstract}


Krol, M., Sixma, H., Meerdink, J., Wiersma, H., Rademakers, J. Exploring young patients' perspectives on rehabilitation care: methods and challenges of organizing focus groups for children and adolescents. Child: Care, Health and Development: 2014, 40(4), 507-514

participants more at ease. For both age groups, the online focus groups proved far less useful, in terms of participation.

\section{INTRODUCTION}

The importance of the patients' perspective in quality of care research is widely recognized (Fung et al. 2008; Delnoij 2009). Patients can provide information that cannot be collected otherwise, for example about how they experience the care process, or the perceived effectiveness of care.

Although many studies have focussed on the preferences and experiences of patients in health care, not every patient group is heard. Children, for instance, are often not included in patient surveys. Even though many studies claim to focus on the experiences of children in health care, often, information reported by parents, as proxies for their children, is used (House et al. 2009; Lindeke et al. 2009). Children themselves, however, have their own healthcare preferences and experiences. These do not necessarily concur with those of their parents (van Beek 2007; Knopf et al. 2008).

Fortunately, the importance of involving children in quality of care research is more and more recognized (Lightfoot et al. 1999; Siebes et al. 2007; Watson et al. 2007; Lindeke et al. 2009; Pelander et al. 2009). Children and adolescents are perfectly able to give their own opinions about their health care, if they are given the right opportunity to do so. Children as young as 8 years old are capable of participating individually in (online) surveys (Borgers et al. 2000; Lindeke et al. 2009). Before this age, however, the cognitive skills necessary for self-reflection and the 'question answering process’ are usually not yet developed (Piaget \& Inhelder 1969; Borgers et al. 2004).

Our research aimed to give young patients an opportunity to speak up for themselves in the development process of two new patient experience surveys on rehabilitation care [new additions to the Consumer Quality Index (CQI), a family of surveys measuring patient experiences in Dutch health care (Delnoij et al. 2006)]. Rehabilitation care covers a variety of specialized care (such as physical, occupational and speech therapy), aimed at enhancing functional abilities of their patients. Also, the cause of the functional disabilities can be diverse, such as congenital disorders, (traffic) accidents, sports injuries or cognitive disorders. In the case of children and adolescents, the first two causes are most common in rehabilitation care. In the Netherlands, each year about 18000 young patients $(<18$ years old) receive rehabilitation care, constituting about $23 \%$ of the total number of rehabilitation patients (Revalidatie Nederland 2011).

In order to develop a valid patient survey, relevant quality items for the specific patient group have to be identified. Our research distinguished two age groups of young patients: children (aged 8-11 years old) and (pre)adolescents (aged 12-15 years old). The division of these age groups was based on developmental differences: in adolescence, young people become more autonomous and may hold different views than they did in their childhood (Kyngäs 2004; Livingston et al. 2007). Because of these developmental differences, Dutch law actually makes a distinction between the responsibilities of healthcare providers regarding these age groups; 
Krol, M., Sixma, H., Meerdink, J., Wiersma, H., Rademakers, J. Exploring young patients' perspectives on rehabilitation care: methods and challenges of organizing focus groups for children and adolescents. Child: Care, Health and Development: 2014, 40(4), 507-514

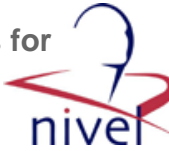

adolescents should be more actively involved by healthcare providers in their care than children (Law on Medical Treatment Agreement 1994).

To explore the preferences and experiences relevant to patients, focus group research can be used (Sofaer 2002). Focus group meetings have proved to be a useful and suitable method for involving a specific group of people, such as patients who visit the same healthcare provider or suffer from the same specific illness (Krueger \& Casey 2000). Focus groups aim to provide an encouraging and safe situation for participants to freely discuss their experiences and opinions, for instance regarding health care. This is also true, with some modifications, for children and adolescents (Peterson-Sweeney 2005).

More recently, online focus groups have also proved to be a popular and accessible way of involving patients in quality of care research (Moloney et al. 2003; Tates et al. 2009). An online forum might prove a useful alternative to a focus group meeting; participating in an online forum can be done from the comfort of one's own house (or any other place that has an Internet connection), regardless the time of day. It also provides more anonymity. Adolescents are usually very familiar with online forums through social media. Nowadays, the same also applies more and more to children (Kennedy et al. 2003; Kenny 2005). There have been encouraging experiences in using online focus groups for obtaining children's and adolescents' views on health care (Zwaanswijk et al. 2007; Tates et al. 2009).

In this article, we will present the organization and design of our focus group meetings and online focus groups. In doing so, we will discuss the usefulness and challenges of both types of focus groups in our research and aim to answer the following research question: To what extent are focus group meetings and online focus groups feasible and applicable strategies for exploring the preferences and experiences of children and adolescents in rehabilitation care?

\section{METHODS}

\section{Recruitment of participants}

The research took place during summer 2011. Young patients from two Dutch rehabilitation centres were recruited to participate. They could choose to either participate in a focus group meeting or in an online focus group. Patients were eligible for selection based on their age (either 8-11 for the children's groups or 1215 years for the adolescents' groups). Also, they should have had at least one appointment at the rehabilitation centre in the past 12 months. As the research involved minors, the invitation was addressed to the children and their parents. The invitation included an outline of the research for the parents and a specific letter for the young patients, which stressed the importance of the research and that participants would receive a gift certificate.

The meetings were situated at the rehabilitation centres. The aim was to organize two meetings per age group in both centres. Also, online focus groups were constructed, one for each age group. The online focus groups consisted of a 1-week online forum. According to the Dutch Medical Research Involving Human Subjects Act this study did not require ethics approval. An explanatory statement of the governmental agency overseeing compliance with the Act, defines medical research as (in short): research aimed at acquiring generalizable results about diseases and health (aetiology, pathogenesis, symptoms, treatment regimes etc.). Also, research without 
Krol, M., Sixma, H., Meerdink, J., Wiersma, H., Rademakers, J. Exploring young patients' perspectives on rehabilitation care: methods and challenges of organizing focus groups for children and adolescents. Child: Care, Health and Development: 2014, 40(4), 507-514

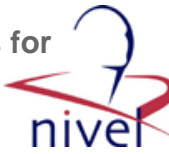

subjecting people to certain procedures or requiring them to act in a certain way, is not medical research in the sense of the Act. However, informed consent was obtained from the participants' parents.

\section{Tailoring focus groups to children and adolescents}

Although there are similarities, a focus group involving children or adolescents demands a slightly different approach than a standard (adult) focus group (PetersonSweeney 2005).

The focus group meetings for children were led by a female professional from the WESP foundation; an organization specialized in involving children as research participants (WESP foundation 2013). During the WESP meetings, she was assisted by one of the researchers. Focus groups with adolescents were led by one of the researchers (H. W.). Meetings were scheduled to last 90-min maximum, including a 15-min break, because it was expected that such meetings would be more tiring for young patients (Heary \& Hennessy 2002). In contrast, meetings for adults usually last $2 \mathrm{~h}$ or more. In standard focus groups, 10 to 12 participants are common. However, because of the potentially intimidating setting of a focus group meeting, we decided to form smaller groups, aiming to recruit six participants for each children's group and eight for each adolescents' group. Also, the moderator and the assistant were alert to any stress, fear or agitation in the participants (Heary \& Hennessy 2002). In order to put the children and adolescents at ease, refreshments, cookies and crisps were available. The atmosphere of the meetings was kept as informal as possible (Peterson-Sweeney 2005). Also, the participants were shown beforehand in which room their parent(s) would be during the meeting.

For adolescents, separate meetings were organized for boys and girls. Puberty marks a period in which adolescents become very self-conscious of themselves and their body. In order not to deter participants from discussing personal subjects such as relationships and sexuality, it was decided to organize same-sex focus groups (Heary \& Hennessy 2002; Wiegerink et al. 2006).

\section{Design of focus group meetings}

The meetings were designed by the WESP foundation. To start off, the moderator gave the participants a short outline of the meeting and stressed the confidentiality of what was said during the meeting (Horner 2000; Heary \& Hennessy 2002). She also emphasized that the participants were 'experts by experience'; the meeting was exclusively about their perceptions and there were no such things as 'good' or 'bad' answers. Participants should feel that their opinions matter and that their input is taken seriously.

In order to build trust and inspire self-confidence, the meetings continued with a short round of introductions (Horner 2000). Subsequently, participants were asked to form pairs and interview each other, using a sheet of questions handed to them by the moderator. The interview covered four different dimensions, pretested by WESP. The dimensions and their associated questions were presented in a logical order so that participants could give their answers and opinions more easily. The four dimensions were: Exploration (e.g. 'Of what use is a rehabilitation centre to a child?'), Feeling ('What do you feel like when you are there?'), Opinion ('What do you think about what happens there?') and finally Advice ('What should be 
Krol, M., Sixma, H., Meerdink, J., Wiersma, H., Rademakers, J. Exploring young patients' perspectives on rehabilitation care: methods and challenges of organizing focus groups for children and adolescents. Child: Care, Health and Development: 2014, 40(4), 507-514

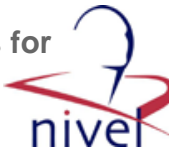

changed?'). In Appendix I, all questions are specified. Answers to the questions were written down on slips of coloured paper by the children who were interviewing; separate colours for separate subjects. At the end of the interview, the roles were reversed. Subsequently, the children glued the paper slips with the answers on flip charts. This provided an overview of the subjects, useful for both the participants and the researchers.

After the interviewing sessions, there was a joint discussion about which aspects of rehabilitation care are important to children or adolescents. For example, the moderator asked the participants to imagine their rehabilitation centre wanted to know how well it performed according to their young patients. Which questions should the centre then ask the children or adolescents who are being treated there? The answers from the participants were written down by the moderator on a flip chart. To conclude the meeting, participants received a gift certificate, and an evaluation form about the meeting, which they could return by mail anonymously.

\section{Design of online focus groups}

For each of the age groups an online focus group (i.e. online forum) was organized, in the same manner as Tates and colleagues (2009). Applicants received the URL of the online forum and a personal username and password. Considerable attention was paid to making the texts on the website clear and comprehensible. Also, some rules of conduct were published on the site, for instance about language (e.g. no profanities) and anonymity. The forums were accessible for a week. Applicants received a reminder a few days before the research began and also on the starting day. On the first 5 days, a question was posted each day by the researchers. These were questions also included in the focus group meetings, as presented in Appendix I (Wednesday's topic being the concluding question of the focus group meetings). Participants were invited to answer the questions and to comment on both the questions and each other's answers. The researchers monitored the discussion and asked additional questions if necessary.

\section{RESULTS}

\section{Response and participation}

Below, Table 1 describes the response on both types of focus groups. Across the two centres, 359 children and 395 adolescents were invited to participate. In the end, 41 (6\%) of these young patients actually participated in either a focus group meeting or an online forum, which was limited. Participation rates were equal for children and adolescents: 13 children and 17 adolescents participated in one of the seven focus group meetings; five children and six adolescents participated in the online forums, having posted at least one reaction on the discussion board.

\section{[TABLE 1]}

\section{Feasibility and applicability of the focus groups}


Krol, M., Sixma, H., Meerdink, J., Wiersma, H., Rademakers, J. Exploring young patients' perspectives on rehabilitation care: methods and challenges of organizing focus groups for children and adolescents. Child: Care, Health and Development: 2014, 40(4), 507-514

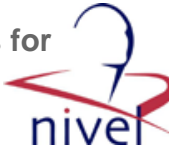

The duration of the meetings proved to be adequate. After $90 \mathrm{~min}$, no new information was obtained from both children and adolescents. A shorter duration, however, would not have been sufficient to complete the programme.

Most children and adolescents were fully motivated to participate, some needed extra encouragement.

With regard to the children's focus groups, a few children needed reassurance from the researchers, but most of them gradually showed more enthusiasm. The mutual interviewing strategy suited most participants. However, some participants resorted to literally repeating the answers their interviewing partner had just given, probably because of insecurity. But for the most part, participants went ahead enthusiastically and seemed to enjoy the experience. This was also reflected by the evaluation forms that were returned afterwards; nine children returned the form and seven of them stated they had liked participating (two said they 'don't know').

With regard to the adolescents' focus groups, the results were more extensive and detailed than those of the children's. With regard to the group meetings, however, both boys' groups proved to be far less informative than the girls' focus groups. This was observable during the meetings, but was also reflected by the results; the girls' lists of answers were far more extensive than those of the boys. Also, in one of the boys' focus groups, participants sought to outdo each other by bragging, resulting in limited responses. Nonetheless, of the 10 evaluation forms that were returned, eight (including four boys) were positive about participating, the other two being neutral. Also, participants were asked on this form what they thought of the same-sex composition of the focus groups. Eight of them (five girls, three boys) stated they had no preference whether it was a same-sex group or a combined group. Only one girl preferred a same-sex group.

With regard to the online forums, these proved less successful than the meetings, both in terms of participation and in results. After several days, many of the applicants had not yet posted answers, or even visited the website. To remedy this, additional e-mail reminders were sent. In the end, though, many of the adolescents had not posted any answers or comments on the website. Also, the majority of the answers to our questions proved to be either very specific or very general. Spurring the participants to clarify their answers, or to elaborate on them, only led to a few additional reactions.

\section{DISCUSSION}

A limited number of children and adolescents participated in the focus groups or the online forums. It proved very difficult to recruit young patients, despite sending the invitations and reminders through the rehabilitation centres and mentioning the gift certificate, although some participants did mention the gift certificate as an extra reason to participate. It should be noted that our issues regarding response rates seem not uncommon for qualitative studies involving children (Goodenough et al. 2003; Kendall et al. 2003; Siebes et al. 2007).

Several reasons, both organizational and personal, might account for the low response rate. First, the meetings and online forums took place during the last week of the summer holiday, so many children might have been away shortly before or during the focus groups and therefore unavailable. Organizing these focus groups during regular school weeks, however, may have overburdened these young patients. 
Krol, M., Sixma, H., Meerdink, J., Wiersma, H., Rademakers, J. Exploring young patients' perspectives on rehabilitation care: methods and challenges of organizing focus groups for children and adolescents. Child: Care, Health and Development: 2014, 40(4), 507-514

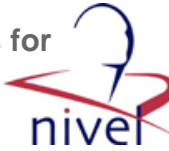

Organizing meetings during school hours is an option, for instance at a school for physically disabled children, although this would include only a part of the target population, i.e. the most severely disabled children and adolescents.

Second, the number of treatments were very limited in the summer period; it was not possible to recruit participants through the employees of the rehabilitation centres. Being asked to participate by their own physician or physiotherapist might have improved the participation rate of young patients.

Also, there are some possible reasons at a personal level. First of all, the letters were sent to the parents, and they might object to their child participating. Also, it is possible that a number of young patients did not feel the research was relevant to them, in case their rehabilitation treatment had ended, or if they did not regularly visit the centre. On the other hand, it may also be that rehabilitation treatment is highly relevant to patients, but they are reluctant to reflect on it, as was also suggested by Siebes and colleagues (2007). This may be because of the profound impact of their health problem on their daily life, such as it is. Especially for children, it may be quite a big step to visit the centre on a day off to talk to strangers about their rehabilitation.

We expected the online forums to be an effective way to involve adolescents in particular, as was found in previous research (Zwaanswijk et al. 2007; Tates et al. 2009). Tates et al. obtained a $23 \%$ response rate from paediatric cancer patients (817 years old). Despite following the exact same research methodology, the response on our online forums was much lower (2\%) and actually proved to be lower than for the focus group meetings, despite all its advantages. A possible explanation for this is that participants in the Tates et al. study were more involved in their health care, cancer being such a serious and life-threatening illness. In rehabilitation care, patients are treated for a wide variety of illnesses and health problems, ranging from minor defects to complex trauma. Of course, in case of the latter, rehabilitation care also has tremendous consequences for the life of a child, so this explanation does not apply to all patients.

It is important to note that qualitative research is used to explore subjects and not to generate generalizable information. Therefore, a limited response does not have to necessarily be problematic, as long as saturation of the information is obtained, and research participants are representative of the population (Strauss \& Corbin 1998). However, the low recruitment rates in our research did limit the generalizability of the focus group results. It would be interesting to investigate the use of social media (twitter, creating a buzz) or other recruitment strategies to increase the awareness of the research. Perhaps by asking children or adolescents to join a research panel. These strategies could increase the commitment.

The setting of a focus group meeting suited most of the participants, but seemed a bit awkward for some of the children. However, the WESP strategy of letting participants interview each other did lead to active participation in the meetings. Letting children talk about their ideas and experiences during activities seems an appropriate and useful strategy. For more complete data collection, it could be considered to audiotape (or even videotape) the meetings, in addition to the written answers of the participants. These recordings could help to identify subjects mentioned by the participants that were not written down, but also more spontaneous remarks made by the children. 
Also, it may have been useful to organize multiple sessions for each group. In this way, participants get to know each other and the researchers better, which will probably let them open up more.

Another suggestion is to perform individual interviews with the youngest patients (aged 11 years and younger). This would avoid the excitement of a group meeting and may make the children feel more at ease in discussing all subjects important to them. Also, this would give the researcher the opportunity to explore answers in depth. During the current meetings, this was not possible. Furthermore, it may be considered to interview children at a location of their own choice, for instance at home. The rehabilitation centre was a familiar location for most participants, but it may have raised negative associations for some of them.

With respect to the same-sex focus groups for adolescents, it is difficult to judge whether the usability of focus group results would benefit from mixed focus groups. On the downside, it might slow down the enthusiasm shown by the girls or increase the bragging by the boys. It should be noted, though, that this concerned an exceptionally young adolescents' focus group (i.e. all three participants were 12 years old). On the upside, it might lead to more balanced results, and most participants stated they had no preference regarding the gender composition of the group. Another reason for the same-sex groups was to make the participants feel comfortable enough to maybe even discuss the way their rehabilitation care affected relationships and sexuality (Wiegerink et al. 2006, 2011). This subject was not mentioned by any of the participants, however. The relevance of sensitive subjects, such as sexuality and social exclusion, could be investigated more thoroughly, perhaps by using a different strategy such as interviews (De Graaf \& Rademakers 2011).

\section{Practical implications}

A few recommendations can be made for future research seeking the opinions and preferences of children and adolescents about rehabilitation care, but also in other healthcare disciplines. First, sufficient attention should be paid to maximizing participation rates, for instance regarding planning, location and arousing the interest of young patients. Second, a single meeting is probably too short to create a sufficiently safe environment for young patients to voice their opinions, especially for children. Repeated meetings may provide them with more confidence and enable the researchers to explore topics more thoroughly. Also, individual interviews could be considered, in addition to focus groups.

The use of online focus groups in the current patient groups has not proved its value.

\section{Conclusion}

The current design proved useful in researching the opinions and preferences of adolescents regarding health care, but less so for children. For both age groups, focus group meetings proved more feasible and useful than online forums. With some adjustments, the (online) focus group design could provide a method for actively involving both age groups in quality of care research.

\section{Key messages}


Krol, M., Sixma, H., Meerdink, J., Wiersma, H., Rademakers, J. Exploring young patients' perspectives on rehabilitation care: methods and challenges of organizing focus groups for children and adolescents. Child: Care, Health and Development: 2014, 40(4), 507-514

An adjusted design for focus group meetings is useful for involving (pre)adolescents (aged 12-15 years) in rehabilitation care in quality of care research.

Additional research is needed into ways of increasing the involvement of children (aged 8-11 years).

Possibilities for enhancing the recruitment rate should be considered.

Online forums proved less successful than focus group meetings.

\section{Acknowledgement}

The authors would like to thank the young patients, their parents and the staff of both participating rehabilitation centres (Revalidatiecentrum Rijndam, Rotterdam and Revalidatie Friesland, Beetsterzwaag) for their contribution.

\section{LITTERATURE}

Borgers, N., De Leeuw, E. \& Hox, J. (2000) Children as respondents in survey research: cognitieve development and response quality. Bulletin de Méthodologie Sociologique, 66, $60-75$.

Borgers, N., Hox, J. \& Sikkel, D. (2004) Response effects in surveys on children and adolescents: the effect of number of response options, negative wording, and neutral MIdPoint. Quality \& Quantity, 38, 17-33.

De Graaf, H. \& Rademakers, J. (2011) The psychological measurement of childhood sexual development in Western societies: methodological challenges. Journal of Sex Research, 48, 118-129.

Delnoij, D. M. (2009) Measuring patient experiences in Europe: what can we learn from the experiences in the USA and England? European Journal of Public Health, 19, 354-356.

Delnoij, D. M., Ten Asbroek, G., Arah, O. A., De Koning, J. S., Stam, P., Poll, A., Vriens, B., Schmidt, P. \& Klazinga, N. S. (2006) Made in the USA: the import of American Consumer Assessment of Health Plan Surveys (CAHPS) into the Dutch social insurance system. European Journal of Public Health, 16, 652-659.

Fung, C. H., Lim, Y. W., Mattke, S., Damberg, C. \& Shekelle, P. G. (2008) Systematic review: the evidence that publishing patient care performance data improves quality of care. Annals of Internal Medicine, 148, 111-123.

Goodenough, T., Williamson, E., Kent, J. \& Ashcroft, R. (2003) 'What did you think about that?' Researching children's perception of participation in a longitudinal genetic epidemiological study. Children \& Society, 17, 113-125.

Heary, C. M. \& Hennessy, E. (2002) The use of focus group interviews in pediatric health care research. Journal of Pediatric Psychology, 27, 47-57.

Horner, S. D. (2000) Using focus group methods with middle school children. Research in Nursing \& Health, 23, 510-517.

House, L. A., Russell, H. F., Kelly, E. H., Gerson, A. \& Vogel, L. C. (2009) Rehabilitation and future participation of youth following spinal cord injury: caregiver perspectives. Spinal Cord: The Official Journal of the International Medical Society of Paraplegia, 47, 882-886.

Kendall, L., Sloper, P., Lewin, R. J. P. \& Parsons, J. M. (2003) The views of young people with congenital cardiac disease on designing the services for their treatment. Cardiology in the Young, 13, 11-19.

Kennedy, C., Charlesworth, A. \& Chen, J. L. (2003) Interactive data collection: benefits of integrating new media into pediatric research. CIN: Computers, Informatics, Nursing, 21, 120-127.

Kenny, A. J. (2005) Interaction in cyberspace: an online focus group. Journal of Advanced Nursing, 49, 414-422.

Knopf, J. M., Hornung, R. W., Slap, G. B., DeVellis, R. F. \& Britto, M. T. (2008) Views of treatment decision making from adolescents with chronic illnesses and their parents: a pilot study. Health Expectations, 11, 343-354. 
Krol, M., Sixma, H., Meerdink, J., Wiersma, H., Rademakers, J. Exploring young patients' perspectives on rehabilitation care: methods and challenges of organizing focus groups for children and adolescents. Child: Care, Health and Development: 2014, 40(4), 507-514

Krueger, R. A. \& Casey, M. A. (2000) Focus Groups. A Practical Guide for Applied Research. Sage Publications, Thousand Oaks, CA, USA.

Kyngäs, H. (2004) Support network of adolescents with chronic disease: adolescents' perspective. Nursing and Health Sciences, 6, 287-293.

Law on Medical Treatment Agreement (1994) [Wet op de geneeskundige behandelingsovereenkomst (WGBO)] [Dutch Medical Treatment Agreements Act]. Available at: http://wetten.overheid.nl/BWBR0007021 (last accessed 7 February 2013).

Lightfoot, J., Wright, S. \& Sloper, P. (1999) Supporting pupils in mainstream school with an illness or disability: young people's views. Child: Care, Health and Development, 25, 267283.

Lindeke, L., Fulkerson, J., Chesney, M., Johnson, L. \& Savik, K. (2009) Children's Perceptions of Healthcare Survey. Nursing Administration Quarterly, 33, 26-31.

Livingston, M. H., Rosenbaum, P. L., Russell, D. J. \& Palisano, R. J. (2007) Quality of life among adolescents with cerebral palsy: what does the literature tell us? Developmental Medicine \& Child Neurology, 49, 225-231.

Moloney, M. F., Dietrich, A. S., Strickland, O. \& Myerburg, S. (2003) Using Internet discussion boards as virtual focus groups. Advances in Nursing Sciences, 26, 274-286.

Pelander, T., Leino-Kilpi, H. \& Katajisto, J. (2009) The quality of paediatric nursing care: developing the Child Care Quality at Hospital instrument for children. Journal of Advanced Nursing, 65, 443-453.

Peterson-Sweeney, K. (2005) The use of focus groups in pediatric and adolescent research. Journal of Pediatric Health Care, 19, 104-110.

Piaget, J. \& Inhelder, B. (1969) The Psychology of the Child. Basic Books, New York, NY, USA.

Revalidatie Nederland (2011) Jaarbeeld 2011 [Annual overview 2011 Rehabilitation Netherlands]. Available at: http://jaarbeeldrevalidatie.nl/ (last accessed 21 November 2012).

Siebes, R. C., Wijnroks, L., Ketelaar, M., Schie, P. E. M., Vermeer, A. \& Gorter, J. W. (2007) Validation of the Dutch Giving Youth a Voice Questionnaire (GYV-20): a measure of the client-centredness of rehabilitation services from an adolescent perspective. Disability and Rehabilitation, 29, 373-380.

Sofaer, S. (2002) Qualitative research methods. International Journal for Quality in Health Care, 14, 329-336.

Strauss, A. L. \& Corbin, J. (1998) Basics of Qualitative Research. Techniques and Procedures for Developing Grounded Theory, 2nd edn. Sage Publications, Thousand Oaks, CA, USA.

Tates, K., Zwaanswijk, M., Otten, R., Van Dulmen, S., Hoogerbrugge, P. M., Kamps, W. A. \& Bensing, J. M. (2009) Online focus groups as a tool to collect data in hard-to-include populations: examples from paediatric oncology. BMC Medical Research Methodology, 9, 15.

Van Beek, F. (2007) Zo willen wij het [This Is How We Want It]. SWP, Amsterdam, the Netherland.

Watson, D., Abbott, D. \& Townsley, R. (2007) Listen to me, too! Lessons from involving children with complex healthcare needs in research about multi-agency services. Child: Care, Health and Development, 33, 90-95.

WESP foundation (2013). [Scientific Educational and Socio-Cultural Projects]. Available at: http://www.wespweb.nl/ (last accessed 5 February 2013)

Wiegerink, D., Roebroeck, M., Bender, J., Stam, H. \& Cohen-Kettenis, P. (2011) Sexuality of young adults with cerebral palsy: experienced limitations and needs. Sexuality and Disability, 29, 119-128.

Wiegerink, D. J., Roebroeck, M. E., Donkervoort, M., Stam, H. J. \& Cohen-Kettenis, P. T. (2006) Social and sexual relationships of adolescents and young adults with cerebral palsy: a review. Clinical Rehabilitation, 20, 1023-1031.

Zwaanswijk, M., Tates, K., Van Dulmen, S., Hoogerbrugge, P. M., Kamps, W. A. \& Bensing, J. M. (2007) Young patients', parents', and survivors' communication preferences in paediatric oncology: results of online focus groups. BMC Pediatrics, 7, 35. 
Krol, M., Sixma, H., Meerdink, J., Wiersma, H., Rademakers, J. Exploring young patients' perspectives on rehabilitation care: methods and challenges of organizing focus groups for children and adolescents. Child: Care, Health and Development: 2014, 40(4), 507-514

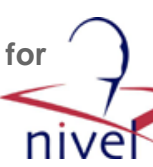

TABLE AND APPENDIX

TABLE 1. RESPONSE ON FOCUS GROUP MEETINGS AND ONLINE FORUMS PER CENTRE AND AGE GROUP

\begin{tabular}{lcclc}
\hline & Invitations & Applications & Participants & Mean age (range) \\
\hline Meetings & & & & \\
$\quad$ Children & $229^{*}$ & 5 & 4 & $10.3(8-12)$ \\
& & 5 & 4 & $9.5(8-11)$ \\
& $130^{*}$ & 7 & (cancelled) & $9.5(9-11)$ \\
Adolescents (f) & 124 & 5 & 4 & $14.5(14-15)$ \\
& 77 & 6 & 5 & $14.4(14-15)$ \\
Adolescents (m) & 131 & 5 & 5 & $13.5(13-15)$ \\
& 63 & 3 & 3 & $12(12-12)$ \\
Online groups & & & $(>1$ post) & \\
Children & 229 & 4 & 3 & $?(9-?)$ \\
& 130 & 3 & 2 & $?(9-?)$ \\
Adolescents & 255 & 11 & 5 & $?(-)$ \\
& 140 & 2 & 1 & $?(-)$ \\
\hline
\end{tabular}

*Applicants could choose from two dates. 
Krol, M., Sixma, H., Meerdink, J., Wiersma, H., Rademakers, J. Exploring young patients' perspectives on rehabilitation care: methods and challenges of organizing focus groups for

\section{APPENDIX I. QUESTIONS FOR INTERVIEWS IN FOCUS GROUP MEETINGS AND ONLINE FOCUS GROUPS}

Focus group meetings

Exploration

What is a rehabilitation centre?

What people are there?

What are you doing in a rehabilitation centre?

Of what use is a rehabilitation centre to a child?

At the beginning, what did you expect from visiting the rehabilitation centre? Did that come true? What did, what did not? Why was that so?

How could children be helped if there was no rehabilitation centre?

Feeling

What does a child feel like, visiting the rehabilitation centre for the first time?

What did you feel like, then?

And how do you feel at the moment?

What helps if you feel bad when you are at the centre?

What makes you feel comfortable when you are at the centre?

Opinion

What do you like about the rehabilitation centre?

What do you like best?

What do you like least?

What would you want to take home with you?

What would you remove?

What do you think of the building?

What do you think of the people who work there?

What do you think of rehabilitating itself?

What do you think of the contact with other children?

Advice

What would the rehabilitation centre look like, if you were the boss? 
How can the people at the centre make sure that children/adolescents are as comfortable as possible?

How can your parents make sure that you are as comfortable as possible?

What can the other children/kids do?

What would you change about the building?

What would you change about the people who work there?

What would you change about the rehabilitation programme?

What would you change about the contact with other children?

Online focus groups

Tuesday What do you think about the rehabilitation centre? What do you like best and what do you like least?

Wednesd Imagine you get to choose a rehabilitation centre to visit for your ay treatment. What would you want to know of each centre before you made your choice?

Thursday What helps if you feel bad when you are at the centre?

Friday How can the people at the centre make sure that children/adolescents are as comfortable as possible?

What would you change about the rehabilitation centre, if you were

Saturday the boss? (This may be anything, for instance something about the building, about the people who work there, your own treatment ...)

Sunday No new statement/question

Monday No new statement/question 